\title{
Effect of Prostaglandin E2 Agonist Omidenepag on the Expression of Matrix Metalloproteinase in Trabecular Meshwork Cells
}

Jeong Yeub Kim, Jae Woo Kim

Department of Ophthalmology, Daegu Catholic University School of Medicine, Daegu, Korea

Purpose: To investigate the effects of prostaglandin E2 agonist omidenepag (OMD) on the expression of matrix metalloproteinase (MMP) in human trabecular meshwork (TM) cells.

Methods: Primarily cultured human TM cells were exposed to $0,1,10$, or $40 \mu \mathrm{mol} / \mathrm{L}$ OMD for 3 days. The permeability through the TM cell monolayer was assessed using carboxyfluorescein. Expressions of messenger ribonucleic acid and protein levels of MMP-1, MMP-3, and MMP-9 were measured by reverse transcription polymerase chain reaction and Western blotting, respectively. Also, the permeability, expression of messenger ribonucleic acid, and protein levels of MMPs were measured after exposure to $1 \mu \mathrm{mol} / \mathrm{L}$ latanoprost free acid (LAT).

Results: OMD and LAT did not affect the cellular survival (all $p>0.05$ ). Each concentration of OMD and LAT did not affect the permeability of carboxyfluorescein significantly (all $p>0.05$ ). LAT increased the level of MMP-1 protein but did not increase the levels of MMP-3 and MMP-9 proteins. Each concentration of OMD did not affect the levels of MMP-1, MMP-3, and MMP9 proteins (all $p>0.05$ )

Conclusions: In TM cells, prostaglandin E2 agonist OMD did not increase the permeability through the TM cell monolayer, and the protein levels of MMPs. These suggest that the direct effect on the trabecular outflow by OMD may be limited.

Key Words: Matrix metalloproteinase, Omidenepag, Permeability, Prostaglandin E2, Trabecular meshwork

Glaucoma is a neurodegenerative optical neuropathy that is characterized by the loss of retinal ganglion cells and their axons and is known to a leading cause of irreversible vision loss [1-3]. Intraocular pressure (IOP) reduction is currently the only evidence-based treatment strategy for

Received: October 28, 2021 Final revision: November 30, 2021 Accepted: December 4, 2021

Corresponding Author: Jae Woo Kim MD, PhD. Department of Ophthalmology, Daegu Catholic University School of Medicine, 33 Duryugongwon-ro 17-gil, Nam-gu, Daegu 42472, Korea. Tel: 82-53-650-4728, Fax: 82-53-627-0133, E-mail: jwkim@cu.ac.kr glaucoma. There are several classes of IOP-reducing medications, including prostanoid FP receptor agonists, such as prostaglandin (PG) analogs, beta-blockers, carbonic anhydrase inhibitors, adrenergic agonists, rho kinase inhibitors, and cholinergics [4,5]. Among them, FP agonists, such as latanoprost, bimatoprost, tafluprost, and travoprost, are the most common medication class used to lower IOP because FP agonists are efficacious, usually well tolerated with few systemic side effects, and need to be taken only once daily, which promotes good treatment adherence.

Prostanoid FP receptor agonists reduce IOP by enhancing uveoscleral outflow [6]. PG analogs elicit their effect 
by binding to specific receptors localized in the cell membrane and nuclear envelope. In the eye, FP and all four EP receptors have been identified in several ocular tissues, including the trabecular meshwork (TM) and the cells of Schlemm's canal $[7,8]$. As PGE2 receptor agonist has been known to reduce IOP since 1988 [9-11], many studies have conducted for clinical use and omidenepag (OMD) isopropyl, a selective EP2 receptor agonist, as a new IOP-lowering ophthalmic solution recently [12-14].

FP agonists are efficacious, usually well tolerated with few systemic side effects. However, PG-associated periorbitopathy has been reported in FP agonist-treated patient. Long-term use of FP agonists causes deepening of the upper eyelid sulcus and pigmentation of the iris and skin surrounding the eye lid $[15,16]$. In contrast, OMD isopropyl reduces these cosmetic adversities which were proved by both experimental and clinical studies [17-20].

Whereas PG analogs have been known to modulate aqueous humor outflow through the uveoscleral pathway by extracellular matrix remodeling, some evidence suggests their action also occurs through the conventional trabecular pathway [21]. A study in ocular hypertensive monkeys demonstrated that OMD isopropyl lowers IOP by increasing the outflow of aqueous humor from both the uveoscleral pathway and the trabecular outflow pathway [22]. This differs from the findings of aqueous humor dynamics studies of most FP agonists which demonstrate that aqueous humor outflow is increased predominantly through the uveoscleral pathway. In a previous study, the outflow facility was accessed by the fluorophotometric method and concluded that OMD isopropyl increases trabecular outflow facility, demonstrating OMD isopropyl has a dual mechanism of action of improving drainage through both outflow pathways [22]. In the TM, extracellular matrix turnover, mediated by matrix metalloproteinase (MMP) and tissue inhibitor of MMP (TIMP), alters IOP and outflow resistance. Thus, OMD may enhance trabecular outflow by increasing the activities of MMPs but the precise mechanism of increasing trabecular outflow by OMD is still uncertain.

In this study, we investigated the effect of OMD on the trabecular outflow by examining the levels of messenger RNA (mRNA) expression and MMPs protein in TM cells. In addition, we investigated the effect of OMD on the trabecular outflow by examining its effect on the permeability of TM cell monolayer.

\section{Materials and Methods}

\section{Cell culture and experimental treatment}

This study followed the tenets of the Declaration of Helsinki and was approved by the institutional review board and the ethics committee of Daegu Catholic University Hospital (No. CR-21-036-L). TM cell cultures were established from enucleated human eyes obtained from an eye bank with written consent. Briefly, TM tissues were excised by dissecting a continuous strand of tissue between the line of Schwalbe and the scleral spur. The excised TM tissues were placed in a sterile culture dish and left undisturbed at $37^{\circ} \mathrm{C}$ in a $5 \% \mathrm{CO}_{2}$ atmosphere. After identifying initial cell growth, the explants were removed, and the cultures were maintained with a medium containing $10 \%$ fetal bovine serum. Cultures after three to five passages were used for experiments. We purchased and used OMD (HY-17642; MedChemExpress, Monmouth Junction, NJ, USA) because OMD isopropyl is hydrolyzed in the eye during corneal penetration to its active metabolite OMD [23]. After attachment, primarily cultured TM cells were then exposed to 0 , 1, 10, or $40 \mu \mathrm{mol} / \mathrm{L}$ OMD for 3 days [19]. In addition, TM cells were also exposed to $0.1 \mu \mathrm{mol} / \mathrm{L}$ latanoprost free acid (LAT; Cayman Chemical, Ann Arbor, MI, USA) for 3 days to compare the effect of OMD with LAT.

\section{MTT assay for cell viability}

Cell survival was determined using a rapid 3-(4,5-dimethylthiazol-2-yl)-2, 5-diphenyltetrazolium bromide (MTT; Sigma, St. Louis, MO, USA) colorimetric assay $[24,25]$. For the assay, $100 \mu \mathrm{L}$ of a MTT stock solution (5 mg MTT/mL phosphate-buffered saline [PBS]) was added to each well and incubated for 4 hours at $37^{\circ} \mathrm{C}$, after which all media was removed from the well. After $0.5 \mathrm{~mL}$ of dimethyl sulfoxide (Sigma) was added to each well, 100 $\mu \mathrm{L}$ of solution from each well was transferred to a 96-well plate and analyzed using a multi-well scanning spectrophotometer ( $\lambda=570 \mathrm{~nm}$; Fluostar Optima, BMG Labtech, Offenburg, Germany).

Measurement of monolayer cell permeability with carboxyfluorescein

A permeability study of the TM cell monolayer was per- 
formed as previously described with minor modification [26-28]. Briefly, primarily cultured human TM cells were incubated in the inner chamber (insert diameter, $12 \mathrm{~mm}$; pore size, $0.4 \mathrm{~mm}$ ) of a 12-well plate (No. 3460; Transwell, Corning, Tewksbury, MA, USA) as $2 \times 10^{4}$ cells $/ \mathrm{mL}$ supplemented with $10 \%$ FBS. After the cells reached confluency, the media was changed to $1 \%$ serum-containing DMEM (Dulbecco Modified Eagle Medium) to avoid the effects of growth factors and proteins in serum; then, the TM cells were exposed to each drug for 3 days. After washing three times with PBS, $50 \mathrm{mM}$ of the tracer carboxyfluorescein (Sigma-Aldrich, St. Louis, MO, USA) was added to each well. The media was collected from the outer well to analyze fluorescence after 2 hours, and the concentration of carboxyfluorescein in the collected media was measured using a spectrofluorometer (Fluostar Optima; BMG Labtech, Offenburg, Germany) with an excitation wavelength of $490 \mathrm{~nm}$ and an emission wavelength of $530 \mathrm{~nm}$.

\section{Measurement of the levels of MMP-1, MMP-3, and MMP-9 mRNA expressions}

Total RNA was extracted using Trizol reagent (Invitrogen, Carlsbad, CA, USA). An RNA denaturation mix consisting of isolated RNA, oligo dT primers, and nuclease-free water was denatured. Reverse transcription polymerase chain reaction (RT-PCR) was performed using oligonucleotide primers specific to MMP-1 (forward primer, TGC AAC TCT GAC GTT GAT CCC AGA; reverse primer, ACT GCA CAT GTG TTC TTG AGC TGC; 122 bp), to MMP-3 (forward primer, CTG GGC CAG GGA TTA ATG GAG; reverse primer, CAA TTT CAT GAG CAG CAA CGA GA; 102 bp) or to MMP-9 (forward primer, ATT TCT GCC AGG ACC GCT TCT ACT; reverse primer, CAG TTT GTA TCC GGC AAA CTG GCT; 195 bp). Two reactions were run in parallel with a second reaction containing only Platinum Taq polymerase to assure that the source of the RT-PCR product was mRNA. Complementary DNA was synthesized by adding prime RT premix, Taq Green Master Mix (Thermo Scientific, Carlsbad, CA, USA), and $10 \mathrm{pM}$ of each forward and reverse primer. The amplification reaction was carried out for 30 cycles on a DNA Engine Cycler (Bio-Rad, Hercules, CA, USA). The amplified PCR products were analyzed using Multi Gauge software (Fujifilm, Tokyo, Japan) after electrophoresis. The level of b-actin was used as an internal standard.
Measurement of the levels of MMP-1, MMP-2, and MMP-3 proteins by Western blotting

Cell extracts were prepared by lysing cells with RIPA buffer (Thermo Scientific). Samples were sonicated and cleared by centrifugation. Supernatant protein concentrations were determined by BCA protein assay reagent (Thermo Scientific). Samples containing equal amounts of protein were separated by NuPAGE $4 \%$ to $12 \%$ Bis-Tris gels (Invitrogen, Carlsbad, CA, USA), followed by transfer of resolved proteins to nitrocellulose membranes using the Xcell SureLock electrophoresis system (Invitrogen). Nonspecific binding was blocked for 1 hour at room temperature. Blots were then probed overnight at $4^{\circ} \mathrm{C}$ with primary antibodies, followed by 1-hour incubations with secondary antibodies conjugated to goat anti-rabbit horse-radish peroxidase (Santa Cruz Biotechnology, Dallas, TX, USA), and then developed by chemiluminescence detection using SuperSignal West Pico Chemiluminescent Substrate (Thermo Scientific). Quantification of the signals was performed using a Gel Doc XR+ system (Bio-Rad). Glyceraldehyde 3-phosphate dehydrogenase was used as an internal standard.

\section{Statistical analysis}

All data represent the average results of at least three independent experiments. Experimental differences between the results of control cultures and a single treatment group were evaluated using Student's $t$-tests. A $p$-value less than 0.05 was considered statistically significant.

\section{Results}

\section{Effect of OMD on the viability of TM cells}

Exposure to $0,1,10$, or $40 \mu \mathrm{mol} / \mathrm{L}$ OMD for 3 days did not significantly affect TM cell survival (all $p>0.05$ ) (Fig. 1). Also, exposure to $0.1 \mu \mathrm{mol} / \mathrm{L}$ LAT did not affect TM cell survival $(p>0.05)$. Thus, the drugs used in this study did not affect cell survival.

Effects of OMD on the TM cell monolayer permeability

To evaluate the effect of OMD on permeability through 
TM monolayer cells, permeability was measured using carboxyfluorescein. As a result, exposure to $0,1,10$, or $40 \mu \mathrm{mol} / \mathrm{L}$ OMD did not affect the concentration of carboxyfluorescein in the outer well significantly compared to nonexposed controls (all $p>0.05$ ) (Fig. 2). Exposure to $0.1 \mu \mathrm{mol} / \mathrm{L}$ LAT did not affect TM monolayer cell permeability $(p>0.05)$

\section{Effects of OMD on the levels of MMP-1, MMP-3, and MMP-9 mRNA of expressions}

Treatment of the TM cells with 1,10 , or $40 \mu \mathrm{mol} / \mathrm{L}$ of OMD did not affect the level of MMP-1 mRNA expression (all $p>0.05$ ) (Fig. 3). On the contrary, treatment of the TM

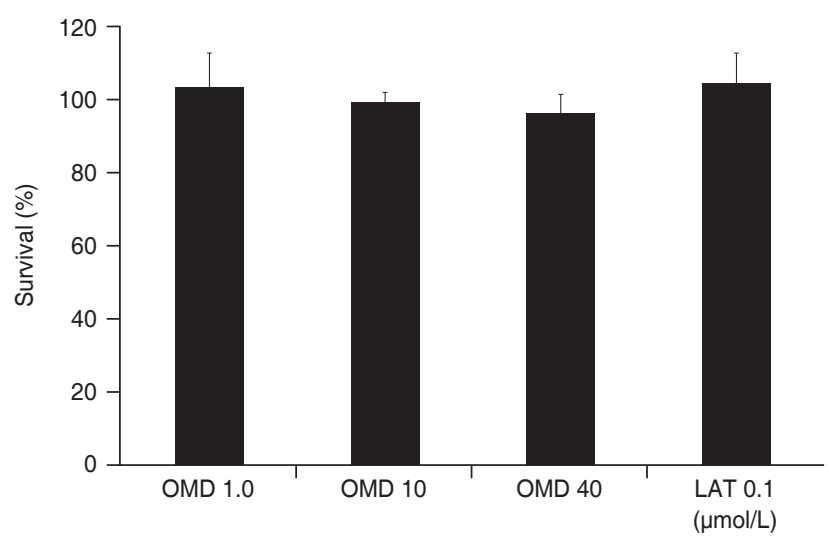

Fig. 1. Effect of omidenepag (OMD) and latanoprost free acid (LAT) on the survival of cultured trabecular meshwork cells. Exposure to OMD or LAT did not affect cell survival significantly.

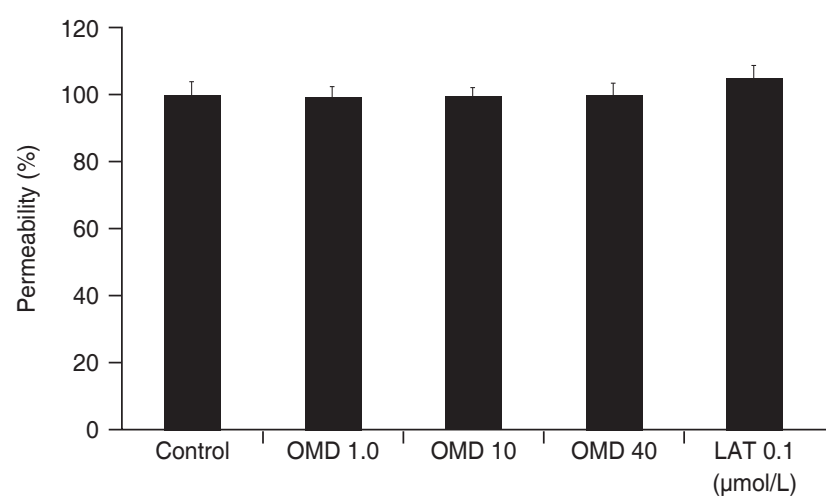

Fig. 2. Effect of omidenepag (OMD) and latanoprost free acid (LAT) on the permeability of cultured trabecular meshwork cell monolayers. Exposure to OMD or LAT did not affect the permeabilities of carboxyfluorescein significantly compared to nonexposed control. Carboxyfluorescein intensity of outer chamber normalized to the mean value obtained using nonexposed control (permeability 100\%). cells with $0.1 \mu \mathrm{mol} / \mathrm{L}$ LAT resulted in an increase in the level of MMP-1 mRNA expression $(p=0.049)$. When treated TM cells with 1, 10, $40 \mu \mathrm{mol} / \mathrm{L}$ OMD or $0.1 \mu \mathrm{mol} / \mathrm{L}$ LAT, there was a tendency to increase the levels of MMP3, MMP-9 mRNA expressions, but statistically not significant respectively (all $p>0.05$ ) (Fig. 4, 5).

\section{Effects of OMD on the levels of MMP-1, MMP-3, and MMP-9 proteins}

Administration of 1,10 , or $40 \mu \mathrm{mol} / \mathrm{L}$ OMD did not sig-

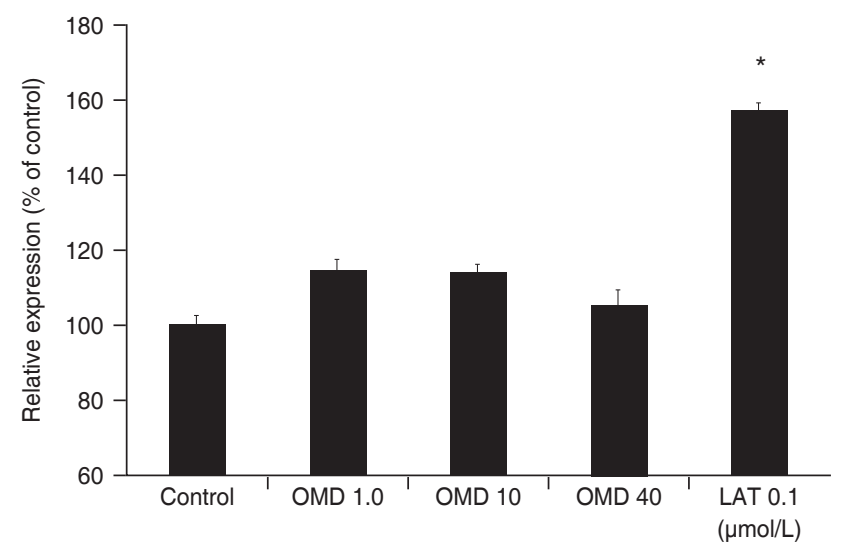

Fig. 3. Effect of omidenepag (OMD) and latanoprost free acid (LAT) on the levels of matrix metalloproteinase-1 messenger ribonucleic acid expression. "In contrast to OMD, exposure to $0.1 \mu \mathrm{mol} / \mathrm{L}$ LAT increased levels matrix metalloproteinase-1 messenger ribonucleic acid expression significantly compared to nonexposed control $(p=0.049)$.

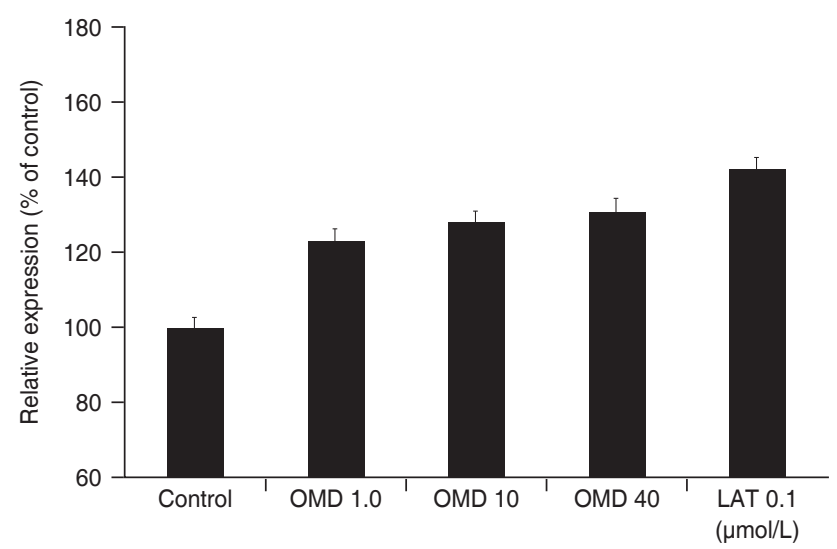

Fig. 4. Effect of omidenepag (OMD) and $0.1 \mu \mathrm{mol} / \mathrm{L}$ latanoprost free acid (LAT) on the levels of matrix metalloproteinase- 3 messenger ribonucleic acid expression. Exposure to OMD or LAT did not affect levels of matrix metalloproteinase-3 messenger ribonucleic acid expression significantly compared to nonexposed control. 
nificantly increased MMP-1 protein levels compared to nonexposed controls (all $p>0.05$ ) (Fig. 6). Exposure to $0.1 \mu \mathrm{mol} / \mathrm{L}$ LAT increased MMP-1 protein level significantly compared to nonexposed controls $(p=0.035)$. When treated TM cells with $1,10,40 \mu \mathrm{mol} / \mathrm{L}$ OMD or $0.1 \mu \mathrm{mol} / \mathrm{L}$ LAT, the levels of MMP-3, or MMP-9 proteins did not significantly differ compared to nonexposed controls (all $p>0.05$ ) (Fig. 7, 8).

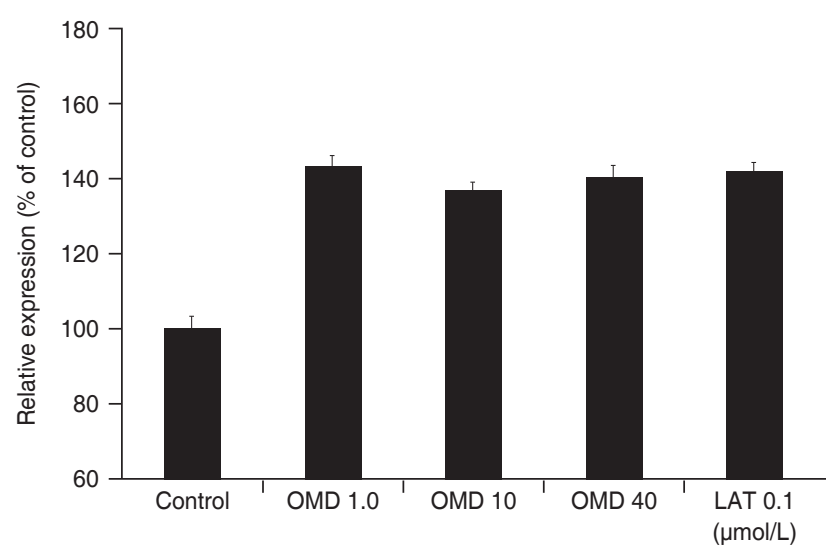

Fig. 5. Effect of omidenepag (OMD) and latanoprost free acid (LAT) on the level of matrix metalloproteinase-9 messenger ribonucleic acid expression. Exposure to OMD or LAT did not affect levels of matrix metalloproteinase-9 messenger ribonucleic acid expression significantly compared to nonexposed control.

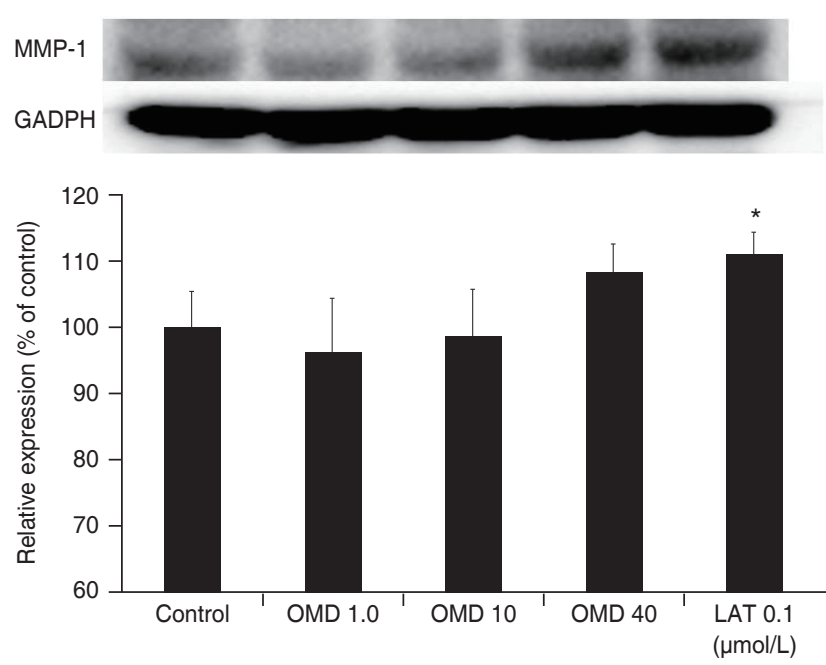

Fig. 6. Effect of omidenepag (OMD) and latanoprost free acid (LAT) on the level of matrix metalloproteinase (MMP)-1 protein. "Exposure to $0.1 \mu \mathrm{mol} / \mathrm{L}$ LAT increased levels of MMP-1 protein significantly compared to nonexposed control $(p=0.035)$. GAPDH $=$ glyceraldehyde 3 -phosphate dehydrogenase.

\section{Discussion}

Controlled extracellular matrix turnover is important in the regulation of aqueous humor outflow facility. In the TM, extracellular matrix turnover, mediated by MMPs alters IOP and outflow resistance [29-32]. Previous study
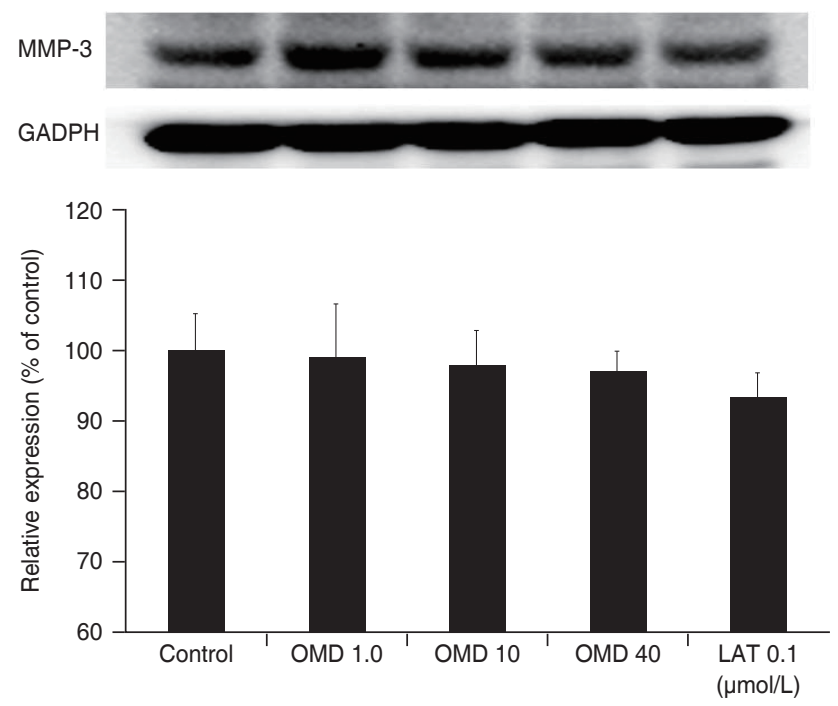

Fig. 7. Effect of omidenepag (OMD) and latanoprost free acid (LAT) on the level of matrix metalloproteinase (MMP)-3 protein. Exposure to OMD or LAT did not affect levels of MMP-3 protein significantly compared to nonexposed control. GAPDH $=$ glyceraldehyde 3-phosphate dehydrogenase.

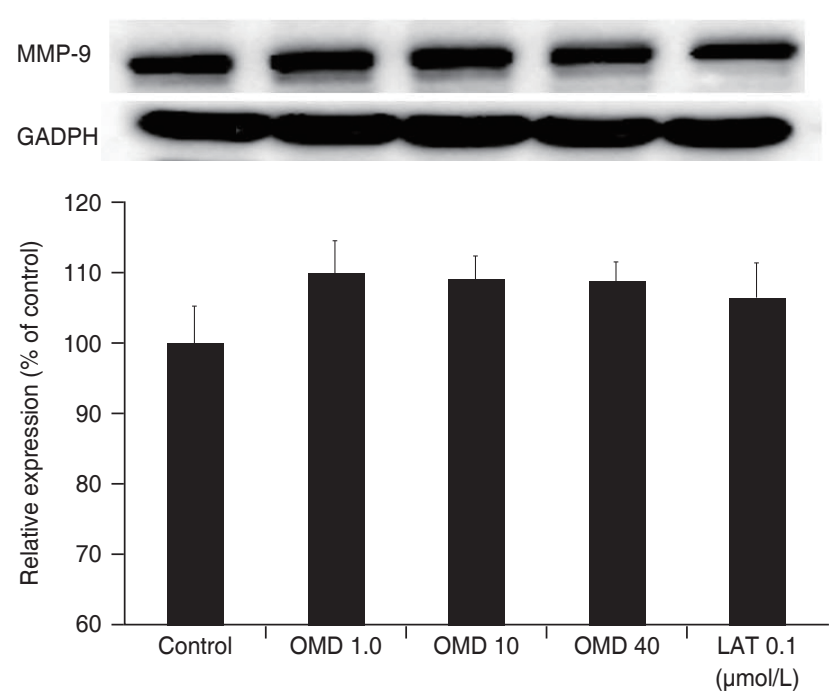

Fig. 8. Effect of omidenepag (OMD) and latanoprost free acid (LAT) on the level of matrix metalloproteinase (MMP)-9 protein. Exposure to OMD or LAT did not affect levels of MMP-9 protein significantly compared to nonexposed control. GAPDH $=$ glyceraldehyde 3-phosphate dehydrogenase. 
showed that PGE2 agonist OMD increases both uveoscleral and trabecular outflow in ocular hypertensive monkeys [22], but the exact roles of OMD on the TM remain uncertain. Although OMD may reduce resistance of TM by modulating MMPs, the direct effect of OMD on the activity of MMPs in TM cell is still obscure. Among MMPs, activities of MMP-1, MMP-3, and MMP-9 are minimal in normal state and their activities are increased with various stimulations [29-32]. Thus, effects of OMD on the MMP-1, MMP-3, and MMP-9 activities were investigated in this study.

Our result reveals that OMD did not affect the levels of MMP-1, MMP-3, and MMP-9 mRNA and protein significantly. Furthermore, OMD did not increase the permeability of TM cell monolayer. Taken together, these results suggest that the direct effect of OMD on the trabecular outflow may be limited.

One of the possible explanations of increasing trabecular outflow despite of limited effect on the activities of MMPs by OMD in TM cells is as follows. The signaling pathways of PGE2 agonist and PGF2a agonist are different. The actions of these agonists vary in the type of second messenger. EP2 act through adenylyl cyclase and cyclic adenosine monophosphate leading to the activation of protein kinase A, while FP causes hydrolysis of phosphatidylinositol, which activates protein kinase $\mathrm{C}$, and causes release of intracellular calcium [6,21]. FP-induced phosphatidylinositol not only increase MMPs levels in the ciliary muscle which in turn cause tissue remodeling but also induce PGE2 synthesis [6]. LAT induces MMP-1 expression in human non-pigmented ciliary epithelial cells through a cyclooxygenase-2-dependent mechanism. After transport of MMP1 in aqueous humor to ciliary muscle and TM, the protease may facilitate outflow of aqueous humor via remodeling of the extracellular matrix of tissues involved in the uveoscleral and trabecular pathway, respectively [33]. The hypothesis that MMPs produced by ciliary cells are secreted into the aqueous humor is supported by the fact that the increased amounts of MMPs in the culture medium of organ explants treated with LAT [34]. Since MMPs produced by the ciliary body are then secreted into the aqueous humor and reach the TM, an increase in ciliary cell MMP production by LAT might ultimately induce an increase in the outflow rates of the TM. Thus, PGE2 may increase trabecular outflow by secreting MMP-1 from the non-pigmented ciliary epithelial cells despite of lacking direct effect on the expression of MMPs in the TM cells.

Another possibility is that EP2 may be involved in conventional outflow effects at the level of the inner wall of Schlemm's canal. IOP changes seen upon treatment with EP2 agonists may be through Schlemm's canal, but not through the TM [35].

FP agonists lower IOP predominantly by increasing uveoscleral outflow and to a lesser extent trabecular outflow facility. A study by $\mathrm{Oh}$ et al. [36] showed that TM cells produce more TIMPs, and less MMPs than ciliary body smooth muscle cells. LAT increases MMPs in TM cells, but the increase of TIMPs in TM cells could be the cause of the observed reduction of MMP activity and account for the greater movement of fluid through the uveoscleral pathway. This is consistent with the notion that LAT lowers IOP by increasing the aqueous humor flow through the uveoscleral route. Although LAT increased MMP-1 activity in this study, the effect of LAT on the trabecular outflow may be less than on the uveoscleral outflow since LAT may also increase TIMPs activity in TM.

There are some limitations in this study. Our in vitro results suggest that OMD does not increase MMP activities in TM directly. Regarding this, further study will be needed to measure MMP concentration in the aqueous humor after administration of OMD isopropyl. Also, long-term effect of OMD on the activities of MMPs in TM cannot be excluded. Since the resistance in trabecular outflow pathway could be affected by Schlemm's canal endothelial cells [37], the effect of OMD on the permeability of Schlemm's canal endothelial cell need to investigate in the future.

In conclusion, PGE2 agonist OMD did not affect activities of MMP in TM and did not increase the permeability of TM cell monolayer. These results suggest that the direct effect of OMD on the trabecular outflow may be limited.

Conflicts of Interest: None.

Acknowledgements: None.

Funding: None.

\section{References}

1. Quigley HA, Broman AT. The number of people with glaucoma worldwide in 2010 and 2020. Br J Ophthalmol 2006;90:262-7.

2. Quigley HA. Glaucoma. Lancet 2011;377:1367-77. 
3. Jonas JB, Aung T, Bourne RR, et al. Glaucoma. Lancet 2017;390:2183-93.

4. Cheema A, Chang RT, Shrivastava A, Singh K. Update on the medical treatment of primary open-angle glaucoma. Asia Pac J Ophthalmol (Phila) 2016;5:51-8.

5. Jayanetti V, Sandhu S, Lusthaus JA. The latest drugs in development that reduce intraocular pressure in ocular hypertension and glaucoma. $J$ Exp Pharmacol 2020;12:53948.

6. Doucette LP, Walter MA. Prostaglandins in the eye: function, expression, and roles in glaucoma. Ophthalmic Genet 2017;38:108-16.

7. Schlotzer-Schrehardt U, Zenkel M, Nusing RM. Expression and localization of FP and EP prostanoid receptor subtypes in human ocular tissues. Invest Ophthalmol Vis Sci 2002;43:1475-87.

8. Biswas S, Bhattacherjee P, Paterson CA. Prostaglandin E2 receptor subtypes, EP1, EP2, EP3 and EP4 in human and mouse ocular tissues: a comparative immunohistochemical study. Prostaglandins Leukot Essent Fatty Acids 2004;71: 277-88.

9. Flach AJ, Eliason JA. Topical prostaglandin E2 effects on normal human intraocular pressure. $J$ Ocul Pharmacol 1988;4:13-8.

10. Woodward DF, Lawrence RA, Fairbairn CE, et al. Intraocular pressure effects of selective prostanoid receptor agonists involve different receptor subtypes according to radioligand binding studies. J Lipid Mediat 1993;6:545-53.

11. Woodward DF, Wang JW, Stamer WD, et al. Antiglaucoma EP2 agonists: a long road that led somewhere. J Ocul Pharmacol Ther 2019;35:469-74.

12. Aihara M, Lu F, Kawata H, et al. Pharmacokinetics, safety, and intraocular pressure-lowering profile of omidenepag isopropyl, a selective, nonprostaglandin, prostanoid EP2 receptor agonist, in healthy Japanese and Caucasian volunteers (phase I study). J Ocul Pharmacol Ther 2019;35:54250.

13. Aihara M, Lu F, Kawata H, et al. Phase 2, randomized, dose-finding studies of omidenepag isopropyl, a selective ep2 agonist, in patients with primary open-angle glaucoma or ocular hypertension. J Glaucoma 2019;28:375-85.

14. Aihara M, Lu F, Kawata H, et al. Omidenepag isopropyl versus latanoprost in primary open-angle glaucoma and ocular hypertension: the phase 3 AYAME study. Am J Ophthalmol 2020;220:53-63.

15. Cracknell KP, Grierson I. Prostaglandin analogues in the anterior eye: their pressure lowering action and side effects. Exp Eye Res 2009;88:786-91.

16. Hollo G. The side effects of the prostaglandin analogues. Expert Opin Drug Saf 2007;6:45-52.

17. Hikage F, Ida Y, Ouchi Y, et al. Omidenepag, a selective, prostanoid EP2 agonist, does not suppress adipogenesis in 3D organoids of human orbital fibroblasts. Transl Vis Sci Technol 2021;10:6.

18. Ida Y, Hikage F, Umetsu A, et al. Omidenepag, a non-prostanoid EP2 receptor agonist, induces enlargement of the 3D organoid of 3T3-L1 cells. Sci Rep 2020;10:16018.

19. Yamamoto Y, Taniguchi T, Inazumi T, et al. Effects of the selective EP2 receptor agonist omidenepag on adipocyte differentiation in 3T3-L1 cells. J Ocul Pharmacol Ther 2020;36:162-9.

20. Oogi S, Nakakura S, Terao E, et al. One-year follow-up study of changes in prostaglandin-associated periorbital syndrome after switch from conventional prostaglandin F2alfa to omidenepag isopropyl. Cureus 2020;12:e10064.

21. Winkler NS, Fautsch MP. Effects of prostaglandin analogues on aqueous humor outflow pathways. J Ocul Pharmacol Ther 2014;30:102-9.

22. Fuwa M, Toris CB, Fan S, et al. Effects of a novel selective EP2 receptor agonist, omidenepag isopropyl, on aqueous humor dynamics in laser-induced ocular hypertensive monkeys. J Ocul Pharmacol Ther 2018;34:531-7.

23. Kirihara T, Taniguchi T, Yamamura K, et al. Pharmacologic characterization of omidenepag isopropyl, a novel selective EP2 receptor agonist, as an ocular hypotensive agent. Invest Ophthalmol Vis Sci 2018;59:145-53.

24. Mosmann T. Rapid colorimetric assay for cellular growth and survival: application to proliferation and cytotoxicity assays. J Immunol Methods 1983;65:55-63.

25. Freimoser FM, Jakob CA, Aebi M, Tuor U. The MTT [3-(4,5-dimethylthiazol-2-yl)-2,5-diphenyltetrazolium bromide] assay is a fast and reliable method for colorimetric determination of fungal cell densities. Appl Environ Microbiol 1999;65:3727-9.

26. Grimes PA, Stone RA, Laties AM, Li W. Carboxyfluorescein: a probe of the blood-ocular barriers with lower membrane permeability than fluorescein. Arch Ophthalmol 1982;100:635-9.

27. Araie M. Carboxyfluorescein. A dye for evaluating the corneal endothelial barrier function in vivo. Exp Eye Res 1986;42:141-50.

28. Lei Y, Stamer WD, Wu J, Sun X. Oxidative stress impact 
on barrier function of porcine angular aqueous plexus cell monolayers. Invest Ophthalmol Vis Sci 2013;54:4827-35.

29. Alexander JP, Samples JR, Van Buskirk EM, Acott TS. Expression of matrix metalloproteinases and inhibitor by human trabecular meshwork. Invest Ophthalmol Vis Sci 1991;32:172-80.

30. Pang IH, Hellberg PE, Fleenor DL, et al. Expression of matrix metalloproteinases and their inhibitors in human trabecular meshwork cells. Invest Ophthalmol Vis Sci 2003;44:3485-93.

31. Keller KE, Aga M, Bradley JM, et al. Extracellular matrix turnover and outflow resistance. Exp Eye Res 2009;88:67682.

32. Vranka JA, Kelley MJ, Acott TS, Keller KE. Extracellular matrix in the trabecular meshwork: intraocular pressure regulation and dysregulation in glaucoma. Exp Eye Res 2015;133:112-25.

33. Hinz B, Rosch S, Ramer R, et al. Latanoprost induces matrix metalloproteinase-1 expression in human nonpigment- ed ciliary epithelial cells through a cyclooxygenase-2-dependent mechanism. FASEB J 2005;19:1929-31.

34. el-Shabrawi Y, Eckhardt M, Berghold A, et al. Synthesis pattern of matrix metalloproteinases (MMPs) and inhibitors (TIMPs) in human explant organ cultures after treatment with latanoprost and dexamethasone. Eye (Lond) 2000;14(Pt 3A):375-83.

35. Wang JW, Woodward DF, Stamer WD. Differential effects of prostaglandin E2-sensitive receptors on contractility of human ocular cells that regulate conventional outflow. Invest Ophthalmol Vis Sci 2013;54:4782-90.

36. Oh DJ, Martin JL, Williams AJ, et al. Effect of latanoprost on the expression of matrix metalloproteinases and their tissue inhibitors in human trabecular meshwork cells. Invest Ophthalmol Vis Sci 2006;47:3887-95.

37. Kaneko Y, Ohta M, Inoue T, et al. Effects of K-115 (Ripasudil), a novel ROCK inhibitor, on trabecular meshwork and Schlemm's canal endothelial cells. Sci Rep 2016;6: 19640. 